\title{
Symptomatic Duodenal Duplication Cyst Treated Endoscopically
}

\author{
Mafalda Sousa Luísa Proença Sónia Fernandes \\ Centro Hospitalar de Vila Nova de Gaia e Espinho, Vila Nova de Gaia, Portugal
}

\section{Keywords}

Duodenal duplication cyst - Endoscopic ultrasound ·

Therapeutic endoscopy

\section{Quisto duodenal sintomático - tratamento endoscópico}

\section{Palavras Chave}

Quisto duplicação duodenal · Ecoendoscopia .

Endoscopia terapêutica

A 21-year-old woman with no past relevant clinical history was admitted to the emergency department for acute abdominal pain. Physical examination revealed normal blood pressure, pulse and temperature with mild epigastric tenderness. Laboratory tests showed leukocytosis $\left(16.35 \times 10^{3} / \mu \mathrm{L}\right)$ and elevated C-reactive protein $(20.53 \mathrm{mg} / \mathrm{dL})$ with normal cholestasis and pancreatic tests. An ultrasound and subsequently a computed tomography scan showed a duodenopancreatic cystic inflammatory lesion with $30 \times 24 \mathrm{~mm}$ in the third portion

\section{KARGER}

E-Mail karger@karger.com www.karger.com/pjg
(C) 2018 Sociedade Portuguesa de Gastrenterologia Published by S. Karger AG, Basel

Karger

Open access

This article is licensed under the Creative Commons AttributionNonCommercial-NoDerivatives 4.0 International License (CC BYNC-ND) (http://www.karger.com/Services/OpenAccessLicense). Usage and distribution for commercial purposes as well as any distribution of modified material requires written permission. of the duodenum with edema of the surrounding mucosa and fat. The common bile and pancreatic duct were normal. Antibiotics were initiated and she was discharged asymptomatic after 13 days.

To clarify the diagnosis, a magnetic resonance cholangiopancreatography revealed a simple cystic lesion in the second portion of the duodenum without enhancement with contrast in the hepatocellular phase (Fig. 1) and endoscopic ultrasound showed a subepithelial anechoic, well-delimited lesion in the second portion of the duodenum with $18 \times 11 \mathrm{~mm}$ arising from the submucosa (Fig. 2), compatible with duodenal duplication cyst. The papilla of Vater was in the base of the lesion and the biliary and pancreatic tree were normal with no communication with the cyst. After multidisciplinary discussion, it was decided to provide endoscopic treatment, which was performed 3 months after the acute episode. The patient was submitted to endoscopically guided fenestration by performing an incision of the cyst with a Mori knife (Fig. 3). A guidewire was placed into the cyst and the cyst wall was deroofed using a sphincterotome. The opening was further widened with a balloon with drainage of transparent fluid. 

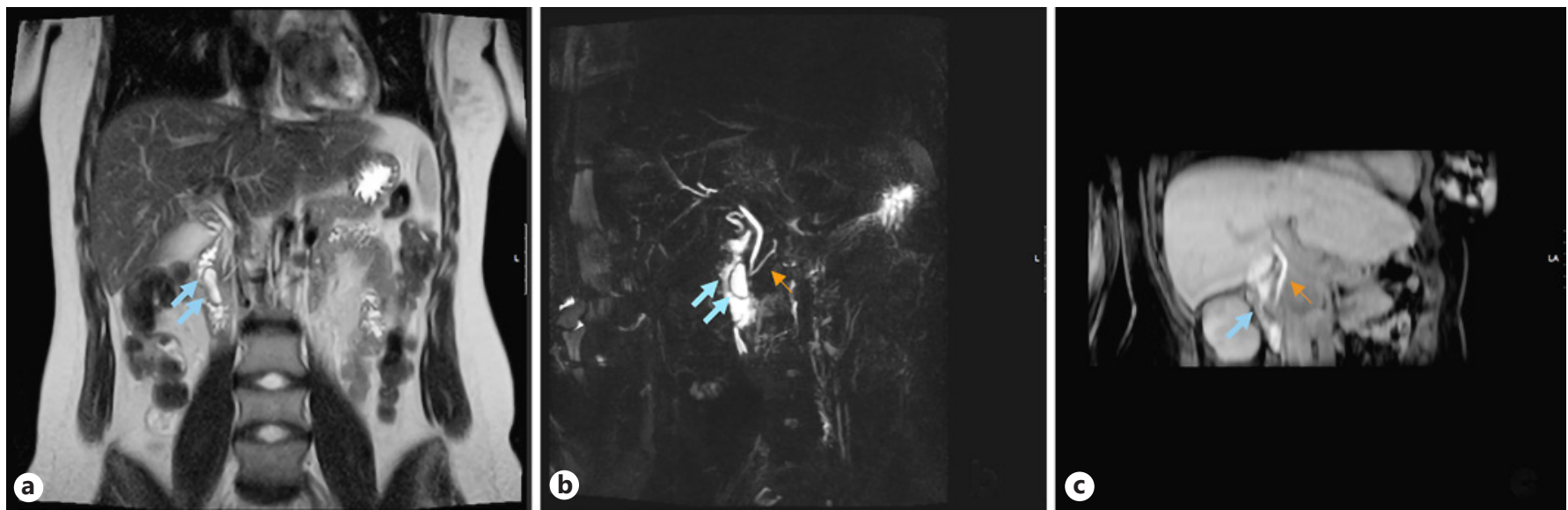

Fig. 1. Magnetic resonance cholangiopancreatography revealed a simple cystic lesion in the second portion of the duodenum (a) with normal common bile duct and pancreatic tree (b). Cyst without enhancement with contrast in the hepatocellular phase (c). Blue arrows - cyst; orange arrows - common bile duct.

Fig. 2. Endoscopic ultrasound showing anechoic, well-delimited lesion in the second portion of the duodenum with $18 \times 11 \mathrm{~mm}$ arising from the submucosa (a) and normal common bile duct (CBD) (b).
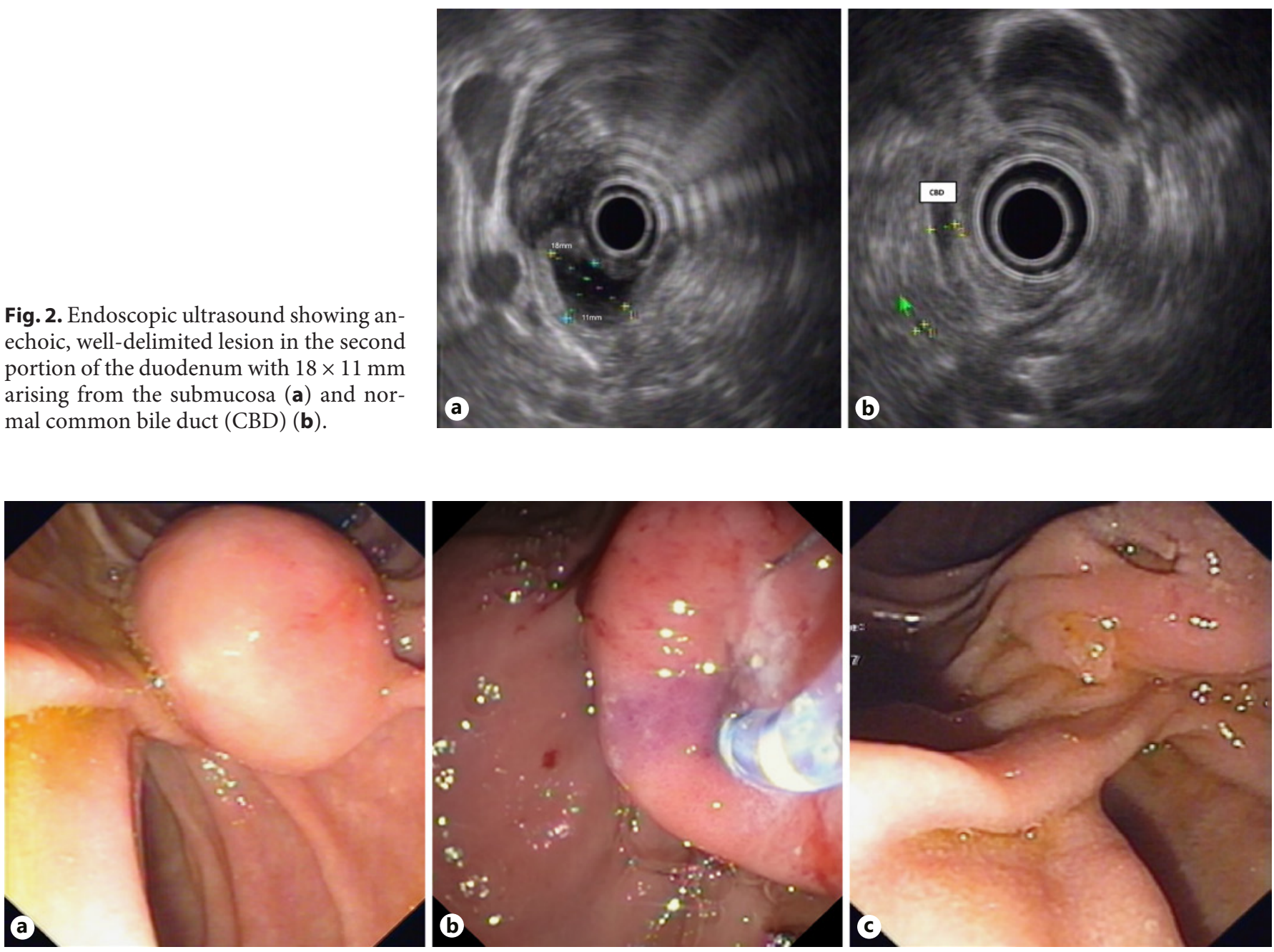

Fig. 3. Duplication cyst in endoscopy (a); fenestration by performing an incision of the cyst with a Mori knife (b); a reminiscence of the cyst (c). 
The patient remains asymptomatic after 6 months of follow-up and a reminiscence of the cyst was observed in endoscopy.

Duodenal duplication cysts are rare and usually asymptomatic and incidentally discovered. Cyst infection has been described in few cases $[1,2]$. Symptomatic duodenal duplication cyst generally mandates treatment [3]. Surgical therapy is associated with significant morbimortality, so, if possible, endoscopic treatment should be preferred since it is safe and effective $[1,2,4]$.

\section{Statement of Ethics}

This study did not require informed consent nor review/approval by the appropriate ethics committee.

\section{Disclosure Statement}

The authors have no conflicts of interest to declare.

References

1 Roy Liu R, Adler D: Duplication cysts: diagnosis, management, and the role of endoscopic ultrasound. Endosc Ultrasound 2014;3: 152-160.

2 Gjeorgjievski M, Manickam P, Ghaith G, Cappell MS: Safety and efficacy of endoscopic therapy for nonmalignant duodenal duplication cysts: case report and comprehensive review of 28 cases reported in the literature. Medicine (Baltimore) 2016;95:e3799.

3 Johnson E, Gopal D: Endoscopic management of symptomatic duodenal duplication cyst. Gastrointest Endosc 2015;82:172.

4 Adler D, Liu R: Duplication cysts: diagnosis, management and role of endoscopic ultrasound. Endosc Ultrasound 2014;3:152-160. 